\title{
An Overview of Implant Stability Measurement
}

\author{
Zeynep Ozkurt Kayhan ${ }^{2}$ and Ender Kazazoglu ${ }^{1 *}$ \\ Department of Prosthodontics, Yeditepe University, Turkey
}

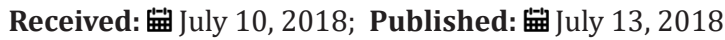

*Corresponding author: Ender Kazazoglu, Department of Prosthodontics, Bagdat Cad. No:238Yeditepe University, Faculty of Dentistry, Kadikoy, Istanbul, Turkey

\begin{abstract}
To achieve and maintain a succesful ossointegration, implant stability is a determining factor in implant dentistry. Implants with sufficient primer stability are claimed to be available for immediate or early loading. In this mini-review, all methods fordental implant stability measurement and recent developments are discussed.
\end{abstract}

Keywords: Implant; Primary stability; Measurement; RFA; Osstell

\section{Introduction}

With Branemark's development of implant systems in the 1960's, dental implants have become a reliable treatment option for tooth loss [1]. One of the most important criteria for implant success is osseointegration [2]. Osseointegration is defined as the direct and functional connection between the implant and the bone surface [3]. Osseointegration also determines implant stability that is occurred in two different stages; primer and secondary stability [4]. Primer stability is related to the mechanical connection of the implant to the cortical bone. Sekonder stability is the biological stability between bone regeneration and remodeling [5]. The majority of the clinicians think that the loading should be applied after the direct relationship between the implant and the bone is obtained [6]. Mobility in implants is considered as a sign of a problem with osseointegration. For this reason, the lack of mobility and the fact that the implant-bone connection can be measured before loading is of great importance for the success of the implants in the future [7]. Although there are several methods of measuring implant stability such as radiographic analysis, insertion torque test, reverse torque tests, shear torque tests, percussion test, periotest and resonance frequency analysis [8-11], none of them provide established measurement standarts yet [12]. However, simple and non-invasive methods are recommended for measuring implant stability and osseointegration [8]. In this mini-review, all methods for dental implant stability measurement and recent developments are discussed.

\section{Methods of Measuring Implant Stability}

Radiographic Analysis: Radiographic analyses are noninvasive methods that can be used at every stage of the healing period. Bitewing radiographs provide information about crestal bone levels, which are considered to be an important criteria for implant success [13]. Crestal bone loss around dental implants of $1.5 \mathrm{~mm}$ during the first year followed by a loss of $0.2 \mathrm{~mm}$ in the subsequent years has been generally considered acceptable for dental implants $[2,14]$. This method alone is not sufficient to determine implant stability, because conventional periapical or panoramic devices only inform us about mesiodistal bone loss [15], and radiographs are incomprehensible unless the change in bone mineralization exceeds 40\% [16]. Among radiographic analyses, computerized tomography is the best method to determine the change in crestal bone level. However, their clinical use is timeconsuming and expensive [17].

Insertion Torque Test: Insertion torque of implants is measured during surgical implant placement [18-20]. There is a significant correlation between bone density and placement torque, which determines implant stability [21,22]. The more intense the bone, the higher the insertion torque and the implant will be stable $[23,24]$. Clinical trials have established a minimum torque value of $20 \mathrm{Ncm}$ and a maximum torque value of $32 \mathrm{Ncm}$ for a successful osseointegration [25].

Reverse Torque Test: This method was found by Roberts et al. [26] and developed by Johansson and Albrektson [27,28]. This method measures the critical torque value that will cut the connection between the implant and bone. This method measures implant stability once the implant has been surgically placed. It has been reported that the reverse torque test may be destructive, causing peri-implanter plastic deformation in the osseointegration 
process and loss of implant [7,4]. This method cannot measure the degree of osseointegration and only used in-vitro studies [9].

Shear Torque Test: Shear torque tests were found by Johansson [20] and developed [18,19,24,29]. During surgery, energy from the electric motor $\left(\mathrm{J} / \mathrm{mm}^{3}\right)$ is given and the delivered energy is measured. According to the amount of force applied by the operator, the energy should be unchanged and the pressure generated should be controlled [18]. It is claimed that this given energy demonstrates the density of the bone and determines the stability of the implant $[18,19,24,29]$. This method is used to determine the density of all kinds of bones. With this method, it is possible to have an idea about implant stability by checking the placement torque [30]. The limitations of the shear torque tests are; the lower limit in the measured energy values is unknown and it can only be used during surgery and bone healing [19].

Percussion Test: Percussion test is one of the easiest tests to understand the level of osseointegration [4,31,32]. This test is based on vibrational acoustic cognition and response theory. Implant is hitted with a metallic tool and osseointegration is evaluated according to the result. A faint sound indicates a good osseointegration, while a faint sound indicates no osseointegration $[31,32]$. This test is a subjective evaluation method that cannot be standardized and may vary according to the clinician's experience [9].

Periotest: Periotest was produced by Siemens in 1997 [33]. It was designed to measure the properties of the periodontium of the tooth. However, it is mostly used to measure implant stability [31]. Periotest is an electromechanical device. It has an electronic monitor and a head that can be used to hit the implant or tooth 16 times in total. The measurement takes 4 seconds. The tapping head has a sensitive tip, recording the duration of the implant or tooth contact. The lower the stability, the longer the contact duration and the higher the Periotest value [33]. The periotest value ranges is as follows; -8 / 0 (good osseointegration, implant can be loaded), +1 / +9 (requires clinical evaluation, implant is not ready for loading) and $+10 /+50$ (inadequate osseointegration) [33,34].

Resonance frequency analysis: Resonance frequency analysis (RFA) is a non-invasive device that can be used clinically in determining the implant loading time, measuring implant stability and osseointegration [35-37]. Clinically, RFA values are correlated with changes in implant stability during bone healing [4]. RFA is evaluated as Implant Stability Quotient (ISQ) from 1 to 100 as a numerical data [35]. The higher the ISQ value, the higher the implant stability [38]. The factors affecting ISQ values are the length, diameter and design of the implant with the quality and quantity of the bone [39].

The first generation of the RFA device contained a sleeve made of stainless steel or titanium and a piezoceramic element. The beam elements in the arm generate vibrations by stimulating frequency sinusoidal signals ranging from $5-15 \mathrm{kHz}$, and the incoming response is read by the frequency analyzer on the computer. The second-generation RFA device amplified the signals generated by the charge amplifier by measuring the piezoceramic arm response in Hertz (Hz) [9]. Then, a more useful device (Osstell, Osstell AB, Göteborg, Sweden) was developed between 1997-2000 [40]. According to initial prototypes, this unit had a different design and function, while the measuring unit contained a transducer that could be autoclaved and calibrated.

In the following years, the implant stability ratio (ISQ) was improved in stability measurements. The ISQ value was recorded between 1 and 100 and was developed as an increasing unit of measurement as the implant stability increased. Then, the SmartPeg device (Osstell AB, Göteborg, Sweden), which can measure without touching and operates with the same electronic principle as the resonance frequency, was produced. In this device, the sinusoidal signal in the transducer passes through the cable to create magnetic pulses, which stimulate the magnetic field. After each pulse, the electronic ring in the measurement probe rises to the measured magnetic field. The second ring in the probe forms the magnetic pulses. The aluminum column has a simpler design that does not require calibration relative to the transducer [41-44].

The transducer of the latest Osstell devices can be used for different implant systems regardless of the implant type, which can perform similar RFA measurements. The transducer consists of an aluminum rod called a smartpeg, magnetic carrier at the tip, which is screwed with a force of approximately 4-6 N/cm. The tip of the device is electromagnetically stimulated without touching the Smartpeg. The incoming signals generate two-way vibration on the Smartpeg, perpendicular to each other. It is recommended that Osstell's measuring head should be positioned at an angle of $900 \mathrm{C}$ with two consecutive measurements [35]. Implant stability values are recorded by reading from the device.

The next generation resonance frequency analyzers after Osstell are: Osstell Mentor, Osstell ISQ, and the Osstell Idx, which operate on the same principle and make measurements using electromagnetic signals from Smartpeg [45]. After all these developments, researchers who produced the Osstell device marketed Penguin RFA (Integration Diagnostics Sweden AB, Göteborg, Sweden), a biocompatible titanium material that can be repeatedly autoclaved with a multi-use transducer (MulTiPeg ${ }^{\mathrm{TM}}$ ), a small pen-shaped battery-powered new generation RFA device [41]. There are various studies conducted on the reliability and ISQ values of RFA devices, and the reliability of all of Osstell's generations from RFA devices has been compared with other methods of measuring implant stability [8,35,29,42-54]. According to author's knowledge, there is only one study which evalated and compared the reliabilty and repeatability of Penguin RFA with Osstell ISQ [55]. It was found that, Osstell ISQ was more reliable than Penguin RFA, and these devices were reliable only in hard interfaces. 


\section{Conclusion}

Primer stability specifies implant-loading times and protocols for implant-supported restorations. Implants with sufficient primer stability are claimed to be available for immediate or early loading. If the primer stabilization of the implants is adequate, the long-term success of the implant would be higher.

With the increasing interest in immediate loading in recent years, researches in the field of primer stabilization has increased. Several methods have been investigated to evaluate the stabilization of implants, but no standardization has been established yet. Histomorphometric analysis is an objective but invasive method with proven accuracy in measuring the distance between the implant and bone. Since invasive methods are rather destructive, they are preferred only in experimental studies. Although all other non-invasive methods are subjective, RFA devices are claimed to be more objective and superior to other methods.

\section{References}

1. Branemark PI, Hansson BO, Adell R(1977) Osseointegrated implants in the treatmant of the edentelous jaw: Experiance from a 10-year period Scand J Plast Reconstr Surg Hand Surg Suppl16: 1-132.

2. Albrektsson T, Zarb G, Worthington P, Eriksson AR (1986) The longterm efficacy of currently used dental implants: A review and proposed criteria of success. Int J Oral Maxillofac Implants1: 11-25.

3. Parithimarkalaignan S, Padmanabhan TV(2013) Osseointegration: An update. J Indian Prosthodont Soc13: 2-6.

4. Meredith N (1998) Assessment of implant stability as a prognostic determinant. Int J Prosthodont; 11: 491-501.

5. Cochran DL, Schenk RK, Lussi A, Higginbottom FL, Buser D (1998) Bone response to unloaded and loaded titanium implants with a sandblasted and acid-etched surface: A histometric study in the canine mandible. J Biomed Mater Res40:1-11.

6. Walker L, Morris HF, Ochi S (1997) Periotest values of dental implants in the first 2 years after second-stage surgery: DICRG interim report no. 8. Dental Implant Clinical Research Group. Implant Dent 6: 207-212.

7. Schnitman PA, Shulman LB (1979) Recommendations of the consensus development conference on dental implants. J Am Dent Assoc98: 373377.

8. Al-Jetaily S, Al-Dosari AA (2011) Assessment of Osstell and Periotest (R) systems in measuring dental implant stability (in vitro study). Saudi Dent J 23: 17-21.

9. Atsumi M, Park SH, Wang HL (2007) Methods used to assess implant stability: Current status. Int J Oral Maxillofac Implants 22: 743-754.

10. Mistry G, Shetty S (2014) Measuring implant stability: A review of different methods. J Dent Implants 4: 165-169.

11. Meredith N, Alleyne D, Cawley P (1996) Quantitative determination of the stability of the implant-tissue interface using resonance frequency analysis. Clin Oral Implants Res 7: 261-267.

12. Gonzalez-Serrano J, Ortega-Aranegui R, Lopez-Quiles J (2017) In vitro comparison of primary stability of two implant designs in D3 bone. Med Oral Patol Oral Cir Bucal 22:e473-477.

13. Attard NJ, Zarb GA (2004) Long-term treatment outcomes in edentulous patients with implant overdentures: the Toronto study. Int J Prosthodont17: 425-433.
14. Smith DE, Zarb GA (1989) Criteria for success of osseointegrated endosseous implants. J Prosthet Dent62: 567-572.

15. Misch CE (2005) Dental Implant Prosthetics, An implant is not a tooth: A conperison of periodontal indexes. Elsevier Mosby: St. Louis.

16. Goodson JM, Haffajee AD, Socransky SS (1984) The relationship between attachment level loss and alveolar bone loss. J Clin Periodontol11: 348359.

17. Misch CE (2005) Dental Implant Prosthetics, Diagnostic imaging and techniques. Elsevier Mosby; St. Louis.

18. Friberg B, Sennerby L, Roos J(1995) Evaluation of bone density using cutting resistance measurements and microradiography: An in vitro study in pig ribs. Clin Oral Implants Res 6: 164-171.

19. Friberg B, Sennerby L, Grondahl K (1999) On cutting torque measurements during implant placement: A 3-year clinical prospective study. Clin Implant Dent Relat Res 1: 75-83.

20. Johansson $P$ (1994) Assessment of bone quality from cutting resistance during implant surgery. Int J Oral Maxillofac Implants 9: 279-288.

21. Beer A, Gahleitner A, Holm A, Tschabitscher M, Homolka P (2003) Correlation of insertion torques with bone mineral density from dental quantitative CT in the mandible. Clin Oral Implants Res14: 616-620.

22. Ikumi N, Tsutsumi S (2005) Assessment of correlation between computerized tomography values of the bone and cutting torque values at implant placement: A clinical study. Int J Oral Maxillofac Implants 20: 253-260.

23. Friberg B, Sennerby L, Linden B, Grondahl K, Lekholm U (1999) Stability measurements of one-stage Branemark implants during healing in mandibles: A clinical resonance frequency analysis study. Int J Oral Maxillofac Surg 28: 266-272.

24. Friberg B, Sennerby L, Roos J, Lekholm U (1995) Identification of bone quality in conjunction with insertion of titanium implants: A pilot study in jaw autopsy specimens. Clin Oral Implants Res6: 213-219.

25. Ottoni JM, Oliveira ZF, Mansini R, Cabral AM (2005) Correlation between placement torque and survival of single-tooth implants. Int J Oral Maxillofac Implants20: 769-776.

26. Roberts WE, Smith RK, Zilberman Y, Mozsary PG, Smith RS (1984) Osseous adaptation to continuous loading of rigid endosseous implants. Am J Orthod 86: 95-111.

27. Johansson CB, Albrektsson $T$ (1991) A removal torque and histomorphometric study of commercially pure niobium and titanium implants in rabbit bone. Clin Oral Implants Res2: 24-29.

28. Johansson CB, Sennerby L, Albrektsson T (1991) A removal torque and histomorphometric study of bone tissue reactions to commercially pure titanium and Vitallium implants. Int J Oral Maxillofac Implants6: 437-41.

29. Friberg B, Sennerby L, Meredith N, Lekholm U 1999) A comparison between cutting torque and resonance frequency measurements of maxillary implantsA 20-month clinical study. Int J Oral Maxillofac Surg28: 297-303.

30. Sullivan D, Sennerby L, Jagger D, Meredith N (2004) A comparison of two methods of enhancing implant primary stability. Clin Implant Dent Relat Res 6: 48-57.

31. Meredith N, Friberg B, Sennerby L, Aparicio C (1998) Relationship between contact time measurements and PTV values when using the Periotest to measure implant stability. Int J Prosthodont11: 269-75.

32. Rasmusson L, Meredith N, Kahnberg KE, Sennerby L (1998) Stability assessments and histology of titanium implants placed simultaneously with autogenous onlay bone in the rabbit tibia. Int J Oral Maxillofac Surg27: 229-35. 
33. Periotest dental measuring instrument for implantology and high quality dentistry. In Periotest Brochure.

34. Schulte W, Lukas D (1993) Periotest to monitor osseointegration and to check the occlusion in oral implantology. J Oral Implantol19: 23-32.

35. Meredith N, Book K, Friberg B, Jemt T, Sennerby L (1997) Resonance frequency measurements of implant stability in vivo. A cross-sectional and longitudinal study of resonance frequency measurements on implants in the edentulous and partially dentate maxilla. Clin Oral Implants Res8: 226-233.

36. Barewal RM, Oates TW, Meredith N, Cochran DL (2003) Resonance frequency measurement of implant stability in vivo on implants with a sandblasted and acid-etched surface. Int J Oral Maxillofac Implants18: 641-651.

37. Uribe R, Penarrocha M, Balaguer J, Fulgueiras N (2005 ) Immediate loading in oral implants: Present situation. Med Oral Patol Oral Cir Bucal10(Suppl 2): E143-153.

38. Nedir R, Bischof M, Szmukler-Moncler S, Bernard JP, Samson J (2004) Predicting osseointegration by means of implant primary stability. Clin Oral Implants Res 15: 520-528.

39. Meredith N, Alleyne D, Cawley P (1996) Quantitative determination of the stability of the implant-tissue interface using resonance frequency analysis. Clin Oral Implants Res 7: 261-267.

40. Sennerby L (2015) Resonance frequency analysis for implant stability measurements: A review. Integration Diagnostics Update1: 1-11.

41. Bertl MH, Weinberger T, Schwarz K, Gruber R, Crismani AG (2012) Resonance frequency analysis: a new diagnostic tool for dental ankylosis. Eur J Oral Sci120: 255-258.

42. Herekar M, Sethi M, Ahmad T (2014) A correlation between bone (B) insertion torque (IT), and implant stability (S): BITS score. J Prosthet Dent 112: 805-810.

43. Glauser R, Sennerby L, Meredith N (2004) Resonance frequency analysis of implants subjected to immediate or early functional occlusal loading. Successful vs. failing implants. Clin Oral Implants Res15: 428-434.

44. Veltri M, GonzalezMartin O, Belser UC (2014) Influence of simulated bone-implant contact and implant diameter on secondary stability: A resonance frequency in vitro study. Clin Oral Implants Res25: 899-904.

45. Kunnekel AT, Nair KC, Naidu EM, Sivagami G (2011) Validation of resonance frequency analysis by comparing implant stability quotient values with histomorphometric data. J Oral Implantol37: 301-308.
46. Turkyilmaz I, Tumer C, Ozbek EN, Tozum TF (2007) Relations between the bone density values from computerized tomography, and implant stability parameters: A clinical study of 230 regular platform implants. J Clin Periodontol34: 716-722.

47. Han J, Lulic M, Lang NP (2010) Factors influencing resonance frequency analysis assessed by Osstell mentor during implant tissue integration: II. Implant surface modifications and implant diameter. Clin Oral Implants Res 21: 605-611.

48. Sim CP, Lang NP (2010) Factors influencing resonance frequency analysis assessed by Osstell mentor during implant tissue integration: I. Instrument positioning, bone structure, implant length. Clin Oral Implants Res21: 598-604

49. Nkenke E, Hahn M, Weinzierl K (2003) Implant stability and histomorphometry: A correlation study in human cadavers using stepped cylinder implants. Clin Oral Implants Res 14: 601-609.

50. Huang HL, Tsai MT, Su KC (2013) Relation between initial implant stability quotient and bone-implant contact percentage: Anin vitro model study. Oral Surg Oral Med Oral Pathol Oral Radiol116: e356-361.

51. Pommer B, Hof M, Fadler A (2014) Primary implant stability in the atrophic sinus floor of human cadaver maxillae: impact of residual ridge height, bone density, and implant diameter. Clin Oral Implants Res25: 109-113.

52. Choi HH, Chung CH, Kim SG, Son MK (2014) Reliability of 2 implant stability measuring methods in assessment of various periimplant bone loss: an in vitro study with the Periotest and Osstell Mentor. Implant Dent23: 51-56.

53. Oh JS, Kim SG, Lim SC, Ong JL (2009) A comparative study of two noninvasive techniques to evaluate implant stability: Periotest and Osstell Mentor. Oral Surg Oral Med Oral Pathol Oral Radiol Endod 107: 513-518.

54. Jaramillo R, Santos R, Lazaro P (2014) Comparative analysis of 2 resonance frequency measurement devices: Osstell Mentor and Osstell ISQ. Implant Dent23: 351-356.

55. Buyukguclu G, Ozkurt-Kayahan Z, Kazazoglu E (2018) Reliability of the Osstell Implant Stability Quotient and Penguin Resonance Frequency Analysis to Evaluate Implant Stability.
This work is licensed under Creative Commons Attribution 4.0 License

To Submit Your Article Click Here: Submit Article
DOI: 10.32474/MADOHC.2018.02.000149

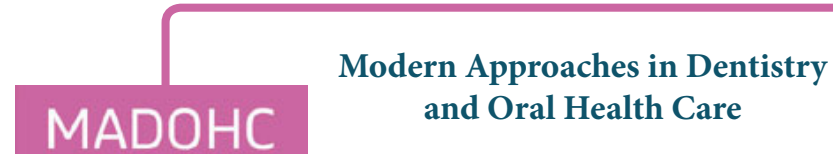

Assets of Publishing with us

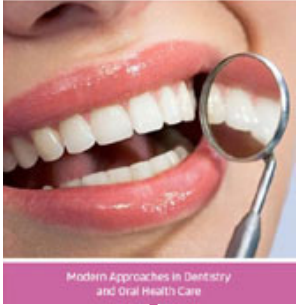

- Global archiving of articles

- Immediate, unrestricted online access

- Rigorous Peer Review Process

- Authors Retain Copyrights

- Unique DOI for all articles 